\title{
B-cell lymphoma 2 is associated with advanced tumor grade and clinical stage, and reduced overall survival in young Chinese patients with colorectal carcinoma
}

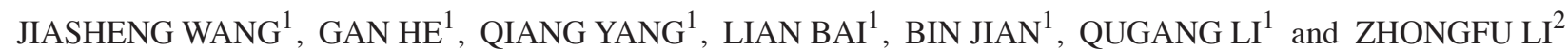 \\ ${ }^{1}$ Department of Gastrointestinal Surgery, Yongchuan Hospital, Chongqing Medical University, \\ Chongqing 402160; ${ }^{2}$ Department of Gastrointestinal Surgery, Chongqing Emergency Medical \\ Center, Center Hospital of Chongqing University, Chongqing 400014, P.R. China
}

Received May 22, 2016; Accepted January 22, 2018

DOI: $10.3892 / \mathrm{ol} .2018 .8489$

\begin{abstract}
The development of biomarkers that accurately and reliably detect colorectal cancer is a promising approach for colorectal cancer screening. Therefore, the objective of the present study was to evaluate the protein expression of $\alpha$-methylacyl-CoA racemase (P504S/AMACR), tumor protein p53 (p53), B-cell lymphoma 2 (Bcl-2) and Ki-67/mindbomb E3 ubiquitin protein ligase 1 (MIB-1) in a population of Chinese patients with colorectal carcinoma. Colorectal tumors with matched normal tissue margins were collected from 148 surgical patients, and the demographic and clinical characteristics were collected. Immunohistochemical staining and western blot analysis of P504S/AMACR, p53, Bcl-2 and Ki-67/MIB-1 were conducted. Statistical analyses were used to compare protein expression in the colorectal tumors and matched normal tissue margins and to identify any associations between them and various clinicopathological parameters. Survival analyses were performed using the Kaplan-Meier method. In the present study, immunohistochemistry and western blot analysis revealed significantly higher expression of all four proteins in colorectal tumors compared with matched normal tissue margins $(\mathrm{P}<0.001)$. Spearman's rank correlation analysis revealed that $\mathrm{Bcl}-2$ expression was negatively correlated with pathological grade and Tumor-Node-Metastasis (TNM) stage $(-0.827$ and -0.388 , respectively; $\mathrm{P}<0.05)$. Bcl-2 expression was revealed to be a significant prognostic indicator of colorectal carcinoma [relative risk (95\% CI), 0.703 (0.552-0.895); $\mathrm{P}<0.05$ ]. The log-rank test revealed a significant association between low
\end{abstract}

Correspondence to: Dr Zhongfu Li, Department of Gastrointestinal Surgery, Chongqing Emergency Medical Center, Center Hospital of Chongqing University, 1 Jiankang Road, Yuzhong, Chongqing 400014, P.R. China

E-mail: 1i_zhongfu@sina.com

Key words: $\alpha$-methylacyl-CoA racemase, tumor protein $\mathrm{p} 53$, B-cell lymphoma 2, Ki-67, mindbomb E3 ubiquitin protein ligase 1, colorectal carcinoma, biomarker
Bcl-2 expression and reduced overall survival $(\mathrm{P}=0.039)$, as well as a significant association between older age ( $>55$ years) and reduced overall survival $(\mathrm{P}<0.001)$ in Chinese patients with colorectal carcinoma. In conclusion, low expression of Bcl-2 is significantly correlated with advanced pathological grade and TNM stage and is a prognostic indicator of reduced overall survival in young Chinese patients with colorectal carcinoma.

\section{Introduction}

Colorectal cancer ranks as the third most common malignancy worldwide, with a global 5-year prevalence of $>3.2$ million cases (1). Due to changes in diet and lifestyle, several increasingly affluent Asian countries (e.g., China, Japan, South Korea and Singapore) have displayed a 2- to 4-fold increase in the incidence of colorectal carcinoma over the past few decades (2). However, non-polypoidal lesions and de novo colorectal neoplasms (i.e., without preceding adenoma) are more common in Asian patient populations. The non-polypoidal lesions are less visible, which poses difficulties in disease screening by conventional imaging and endoscopy (2). Therefore, the development of alternative screening methods for colorectal carcinoma is particularly important.

Early detection of colorectal cancer in its localized or pre-invasive form is a more realistic approach to screening (3). Current screening strategies, including fecal occult blood testing and colonoscopy, have poor levels of patient acceptability (4). The development of peripheral blood protein biomarkers that are able to accurately and reliably detect colorectal cancer at its earliest stages appears to be promising alternative approach for colorectal cancer screening (5).

$\alpha$-methylacyl-CoA racemase (P504S/AMACR) is overexpressed in colorectal adenomas and cancer, and has been demonstrated to be associated with advanced distal colorectal adenoma (6) and tumor differentiation (7). Furthermore, an inverse correlation was demonstrated between p53 and B-cell lymphoma 2 (Bcl-2) expression in colorectal tumorigenesis, and abnormal activation of Bcl-2 inhibited apoptosis in vivo (8). The Ki-67 labeling index is positively correlated with poor survival in colorectal cancer patients (9). Therefore, the objective of the present study was to evaluate the protein 
expression of four key genes, P504S/AMACR, p53, Bcl-2 and $\mathrm{Ki}-67 /$ mindbomb E3 ubiquitin protein ligase 1 (MIB-1), in a population of Chinese patients with colorectal carcinoma. The present study aimed to shed light on the potential applicability of these four proteins as diagnostic biomarkers for colorectal carcinoma in Chinese patient populations.

\section{Materials and methods}

Patients and tumor samples. Frozen tumor tissues with matched normal tissue margins were collected from 148 Han Chinese patients (68 males and 80 females; with a mean age of 50 years old, and the ranging from 25-75 years old) that had undergone surgery at Yongchuan Hospital (Chongqing Medical University, Chongqing, China) from January 2015 to January 2016. For each patient, the following relevant demographic and clinical data were collected: i) Hospital/surgery location (city, country); ii) patient age (years); iii) patient sex; iv) risk factors [e.g., body mass index (BMI), smoking status and excessive alcohol consumption (i.e., a male consuming $>4$ drinks/day or $>14$ drinks/week; or a female consuming $>3$ drinks/day or $>7$ drinks/week)] (10); v) tumor characteristics, including pathological grade of tumor cells (G1-G4) (11), Clinical stage (T1-T4), samples were staged according to the American Joint Committee on CancerTNM staging system(12); and vi) survival time post-surgery (months).

Immunohistochemical staining. Immunohistochemical staining was performed using an Ultrasensitive ${ }^{\mathrm{TM}}$ SP kit (cat. no. KIT-0105M, Maixin Biotech Co., Ltd., Fuzhou, China) and diaminobenzidine (DAB; Fuzhou Maixin Biotech Co., Ltd., Fuzhou, China), according to the manufacturer's protocols. Briefly, $4-\mu \mathrm{m}$ thick paraffin-embedded sections, which were fixed with $4 \%$ formaldehyde at $20^{\circ} \mathrm{C}$ for $24 \mathrm{~h}$, were xylene-deparaffinized at $60^{\circ} \mathrm{C}$ for 1 hour, rehydrated in a descending alcohol series and rinsed in phosphate-buffered saline (PBS). Antigen retrieval was performed by placing the slides in boiling citric acid buffer $(\mathrm{pH} \mathrm{6.0)}$ for $5 \mathrm{~min}$. The sections were subsequently incubated in 3\% hydrogen peroxide in methanol at room temperature for $20 \mathrm{~min}$ to quench endogenous peroxidase activity. Non-immune serum albumin (5\%; Beyotime Institute of Biotechnology, Haimen, China) was used to block non-specific binding at $20^{\circ} \mathrm{C}$ for $5 \mathrm{~min}$. The tissue sections were then incubated at $37^{\circ} \mathrm{C}$ for $2 \mathrm{~h}$ with the following monoclonal primary antibodies: sheep anti-P504S/AMACR (cat. no. AF7508-SP; dilution, 1:500), rabbit anti-p53 (cat. no. AF 1355; dilution, 1:2,000), mouse anti-Bcl-2 (cat no. AF 810; dilution, 1:500) and sheep anti-Ki-67/MIB-1 (cat no. AF 7617; dilution, 1:800) (all from R\&D Systems Inc., Minneapolis, MN, USA). Next was an incubation with biotinylated goat anti-rat IgG secondary antibodies (cat. no.; NL013, dilution, 1:1,000; $\mathrm{R} \& \mathrm{D}$ Systems) at $37^{\circ} \mathrm{C}$ for $30 \mathrm{~min}$ followed by a streptavidin horseradish peroxidase complex, according to the instructions of Ultrasensitive ${ }^{\mathrm{TM}}$ SP kit, with intermittent PBS rinses. Immunoreactivity was visualized with diluted DAB. Finally, sections were rinsed with distilled water, and counterstained at $37^{\circ} \mathrm{C}$ for $5 \mathrm{~min}$ with Mayer's hematoxylin and histomounted. As a negative control, the primary antibody was replaced with an equal amount of normal human/rabbit/rat/mouse IgG. The positive controls were cancer cell lines with known positive expression of P504S/AMACR, p53, Bcl-2 or Ki-67/MIB-1.

Evaluation of immunohistochemistry. Images of stained sections were captured in a series of 10 randomly selected high-power fields with a laser scanning confocal microscope (Olympus Corp., Tokyo, Japan) at magnification, $\mathrm{x} 400$. The sections were then scored by the proportion and staining intensity of positively stained tumor cells. The "proportion score' of positively stained tumor cells was determined as follows: 0 , no positive tumor cells; $1,<10 \%$ positive tumor cells; $2,10-50 \%$ positive tumor cells; and $3,>50 \%$ positive tumor cells. The 'staining intensity' score was determined as follows: 0 , no staining; 1 , weak staining/light yellow; 2 , moderate staining/yellow-brown; and 3, strong staining/brown. Immunohistochemical staining was scored independently by two investigators blinded to the clinicopathological findings. Cases with score discrepancies were re-reviewed simultaneously by the original two investigators and a senior pathologist until a consensus was reached.

The 'staining index' was then calculated as the staining intensity score multiplied by the proportion score. Using this method, a staining index was obtained for P504S/AMACR, p53, Bcl-2 and Ki-67/MIB-1 in colorectal specimens, with scores of $0,1,2,3,4,6$ or 9 for each protein biomarker. Subsequently, cut-off values (Table I) for immunoreactivity for each protein biomarker were based on measuring heterogeneity by the sequential association analysis for SPA progression. This cut-off point was used to distinguish between 'low' and 'high' expression of each protein biomarker.

Western blot analysis. Total protein was extracted from the colorectal cancer and matched normal tissue margin specimens with Cell Extraction Buffer (cat. no. FNN0011; Thermo Fisher Scientific, Inc., Waltham, MA, USA). Protein concentrations were determined using a bicinchoninic acid protein assay kit, and $30 \mu \mathrm{g}$ protein per sample was separated by $8 \%$ SDS-PAGE and transferred onto a methanol-activated nitrocellulose filter membrane (Bio-Rad Laboratories, Inc., Hercules, CA, USA). Prior to immunoblotting, membranes were blocked within $5 \%$ skimmed dry milk at $37^{\circ} \mathrm{C}$ for $2 \mathrm{~h}$. Expression levels were normalized to $\beta$-actin (dilution, 1:1,000; cat. no. MAB8929; R\&D Systems). The following primary monoclonal antibodies were diluted in buffer and incubated at $4^{\circ} \mathrm{C}$ overnight: Sheep anti-P504S/AMACR (cat. no. AF7508-SP; R\&D Systems Inc.; dilution, 1:1,000), rabbit anti-p53 (cat. no. AF1355; R\&D Systems Inc.; dilution, 1:2,000), mouse anti-Bcl-2 (cat no. AF810; R\&D Systems Inc.; dilution, 1:1,000) and mouse anti-Ki-67/MIB-1 (cat no. AF7617; R\&D Systems Inc.; dilution, 1:1,200). Following washing in TBST, membranes were incubated with a horseradish peroxidase-conjugated goat anti-rat secondary antibody (cat. no. ab7097; dilution, 1:1,000; Abcam, Cambridge, UK) for $1 \mathrm{~h}$ at room temperature. This experiment was repeated three times. Bands were detected using a SuperEnhanced chemiluminescence kit (cat. no. P1010; Applygen Technologies, Inc., Beijing, China).

Statistical analysis. All data were analyzed using SPSS 13.0 for Windows (SPSS, Inc., Chicago, IL, USA). $\chi^{2}$ and Fisher's exact tests were used to compare P504S/AMACR, 
Table I. Results of ROC curve analysis of protein biomarkers and determination of the cut-off values.

\begin{tabular}{lccccc}
\hline Protein & $\begin{array}{c}\text { Proportion of } \\
\text { IHC staining }\end{array}$ & $\begin{array}{c}\text { Area under } \\
\text { ROC curve }\end{array}$ & $\begin{array}{c}\text { Cut-off } \\
\text { value, } \%\end{array}$ & Sensitivity, \% & Specificity, \% \\
\hline P504S/AMACR & $6.53 \pm 4.51$ & 0.62 & 8 & 60.2 & 85.1 \\
p53 & $10.39 \pm 5.28$ & 0.65 & 11 & 66.7 & 78.3 \\
Bcl-2 & $18.30 \pm 13.20$ & 0.72 & 21 & 61.4 \\
Ki-67/MIB-1 & $10.20 \pm 7.28$ & 0.70 & 13 & 71.6 \\
\hline
\end{tabular}

ROC, receiver operating characteristic; IHC, immunohistochemistry; AMACR, $\alpha$-methylacyl-CoA racemase; p53, tumor protein p53; Bcl-2, B-cell lymphoma 2.

Table II. Immunohistochemical analysis of four proteins in colorectal carcinoma tumors and matched normal tissue margins (control).

\begin{tabular}{|c|c|c|c|c|}
\hline \multirow[b]{2}{*}{ Variable } & \multicolumn{2}{|c|}{ Tissue type, $\mathrm{n}$} & \multirow[b]{2}{*}{$\chi^{2}$ value } & \multirow[b]{2}{*}{ P-value } \\
\hline & Tumor & Control & & \\
\hline P504S/AMACR expression & & & 88.80 & $<0.001^{\mathrm{a}}$ \\
\hline High & 76 & 4 & & \\
\hline Low & 72 & 144 & & \\
\hline Bcl-2 expression & & & 97.93 & $<0.001^{\mathrm{a}}$ \\
\hline High & 104 & 20 & & \\
\hline Low & 44 & 128 & & \\
\hline p53 expression & & & 76.85 & $<0.001^{\mathrm{a}}$ \\
\hline High & 88 & 16 & & \\
\hline Low & 60 & 132 & & \\
\hline Ki-67/MIB-1 expression & & & 50.71 & $<0.001^{\mathrm{a}}$ \\
\hline High & 72 & 16 & & \\
\hline Low & 76 & 132 & & \\
\hline
\end{tabular}

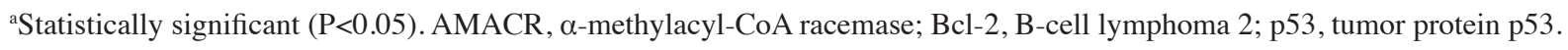

p53, Bcl-2 and Ki-67/MIB-1 protein expression (from the immunohistochemical 'staining index') in the colorectal tumors and matched normal tissue margins and various clinicopathological parameters (e.g., age, sex, BMI and smoking status). The Student's t-test was used to analyze the western blotting results. In order to confirm the correlations between P504S/AMACR, p53, Bcl-2 and Ki-67/MIB-1 protein expression and clinicopathological parameters, Spearman's rank correlation analysis was applied. To determine whether P504S/AMACR, p53, Bcl-2 and Ki-67/MIB-1 expression levels were independent prognostic factors in patients with colorectal carcinoma, prognostic relevance was evaluated using multivariate Cox regression analysis. $\mathrm{P}<0.05$ was considered to indicate a statistically significant difference. Survival analysis was performed using the Kaplan-Meier method, followed by the log-rank test (13).

\section{Results}

P504S/AMACR, p53, Bcl-2 and Ki-67/MIB-1 protein levels are increased in colorectal tumor tissues compared with normal tissue margins. Immunohistochemical analysis revealed that a significantly greater proportion of colorectal tumors exhibited a high expression of all four proteins (P504S/AMACR, p53, Bcl-2 and Ki-67/MIB-1), compared with matching normal tissue margins (Table II; Fig. 1). Additionally, western blot analysis revealed significantly higher expression of the same four proteins in colorectal tumors compared with matching normal tissue margins (all $\mathrm{P}<0.001$; Fig. 2).

Higher expression of $\mathrm{Bcl}-2$ was observed in patients $>55$ years of age, while a lower expression was observed in carcinomas at advanced pathological grades and TNM stages. Statistical analysis comparing P504S/AMACR, p53, Bcl-2 and Ki-67/MIB-1 protein expression in colorectal tumors with various clinicopathological parameters (e.g., age, sex, BMI and smoking) revealed that $\mathrm{Bcl}-2$ expression was significantly associated with patient age ( $>55$ vs. $<45$ years), pathological grade, and TNM stage (all $\mathrm{P}<0.05$; Table III). Additionally, the Spearman's rank correlation analysis revealed that Bcl-2 expression, based on IHC score, was negatively correlated with pathological grade $(\mathrm{r}=-0.827 ; \mathrm{P}<0.001)$ and $\mathrm{TNM}$ stage $(r=-0.388 ; \mathrm{P}=0.018)$. 
Bcl-2 may serve as a prognostic indicator of colorectal carcinoma. To determine whether P504S/AMACR, p53, Bcl-2 and Ki-67/MIB-1 expression levels are independent prognostic indicators of colorectal carcinoma, The survival rate was considered to indicate prognosis, and was evaluated by multivariate Cox regression analysis. Only Bcl-2 expression displayed statistical significance as a prognostic indicator of colorectal carcinoma with a relative risk value of 0.703 (95\% CI, 0.552-0.895; P<0.05; Table IV).

Older patients and those with a lower expression of Bcl-2 exhibit a reduced overall survival time. Based on the aforementioned results, survival analysis based on age and $\mathrm{Bcl}-2$ expression was performed using the Kaplan-Meier method. The Kaplan-Meier curves are plotted in Fig. 3. Log-rank testing revealed that low expression of $\mathrm{Bcl}-2$ in patients was associated with a reduced overall survival time when compared with patients with a higher expression of $\mathrm{Bcl}-2(\mathrm{P}=0.039)$, and that older age ( $>55$ years) was associated with a reduced overall survival time $(\mathrm{P}<0.001)$.

\section{Discussion}

The aim of the present study was to evaluate the protein expression of four key genes, P504S/AMACR, p53, Bcl-2 and $\mathrm{Ki}-67 / \mathrm{MIB}-1$, in order to assess their potential applicability as diagnostic biomarkers of colorectal carcinoma in a population of Chinese patients. Although a significantly higher expression of all four proteins was observed in colorectal tumors compared with the matching normal tissue margins (as determined by immunohistochemistry and western blot analysis), only Bcl-2 downregulation was significantly correlated with advanced pathological grade and TNM stage in these patients. Additionally, Bcl-2 downregulation was revealed to be a prognostic indicator of a reduced overall survival time.

Apoptosis is well-established as a highly conserved process for eliminating damaged cells in multicellular organisms $(14,15)$. Therefore, defects in apoptotic pathways may result in the survival and proliferation of pre-malignant cells, which eventually leads to the development of human cancer $(14,16)$. In particular, the Bcl-2 protein family has been identified as a key set of apoptotic regulators that conduct the following three activities: i) Promotion of cell survival (e.g., Bcl-2 and Bcl-xL); ii) initiation of cell death (e.g., Bcl-2-interacting mediator of cell death and Bcl-2-interacting domain); and iii) activation of apoptotic effector pathways (e.g., Bcl-2-associated $\mathrm{X}$ protein and $\mathrm{Bcl}-2$ homologous antagonist killer) (13). With respect to Bcl-2 and tumorigenesis, elevated Bcl-2 gene expression has been positively correlated with a poorer patient prognosis in colorectal cancer, prostate cancer, bladder cancer, small cell lung cancer, breast cancer, melanoma and acute myeloid leukemia (17). Furthermore, a previous study demonstrated that higher Bcl-2 expression contributes to resistance to chemotherapy and radiation therapy (17).

In contrast with these conventional findings, the present study revealed that $\mathrm{Bcl}-2$ expression was significantly correlated with advanced pathological grade and TNM stage in addition to reduced overall survival time in this Chinese colorectal carcinoma patient population. This phenomenon may be explained through colorectal tumor biology. In the colon, Bcl-2 has been demonstrated to be more highly

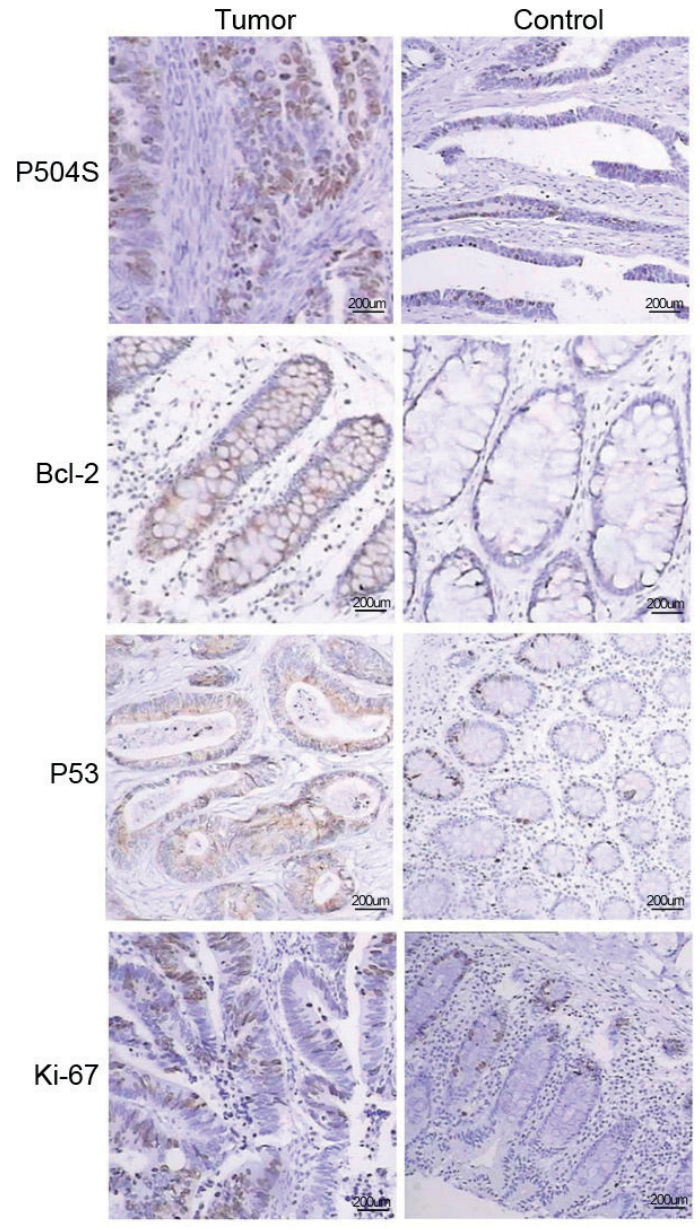

Figure 1. Immunohistochemistry of the four proteins in the colorectal tumors and matching normal tissue margins (control). Representative images of the expression of P504S, Bcl-2, p53 and Ki-67 in colorectal tumors and matching normal tissue margins are shown. P504S, $\alpha$-methylacyl-CoA racemase; Bcl-2, B-cell lymphoma 2; p53, tumor protein p53.

expressed in adenomas than in carcinomas $(18,19)$. As a result, colorectal tumors that retain their $\mathrm{Bcl}-2$ expression tend to display adenoma-like characteristics and are often less aggressive, while tumors with reduced $\mathrm{Bcl}-2$ expression tend to be more aggressive (20).

In terms of tumor characteristics and clinical outcomes, the results of the present study are in line with those of several previous studies in colorectal cancer patients. Biden et al (19) observed a significant negative association between $\mathrm{Bcl}-2$ expression and microsatellite instability, as well as a significant positive association between $\mathrm{Bcl}-2$ expression and patient survival. Ofner et al (21) associated Bcl-2 downregulation with increased tumor size, decreased lymphocytic infiltration and an increased likelihood of a poor clinical outcome. Baretton et al (22) demonstrated that Bcl-2-positive carcinomas are associated with a significantly longer disease-free survival time. Sinicrope et al (23) demonstrated that a high Bcl-2 expression is an independent predictor of improved relapse-free survival, but not overall survival, following adjustment for proliferative index, DNA ploidy and ethnicity. Bhatavdekar et al (24) observed a positive correlation between $\mathrm{Bcl}-2$ expression and a poor survival outcome in patients with UICC/AJCC stage I and III 


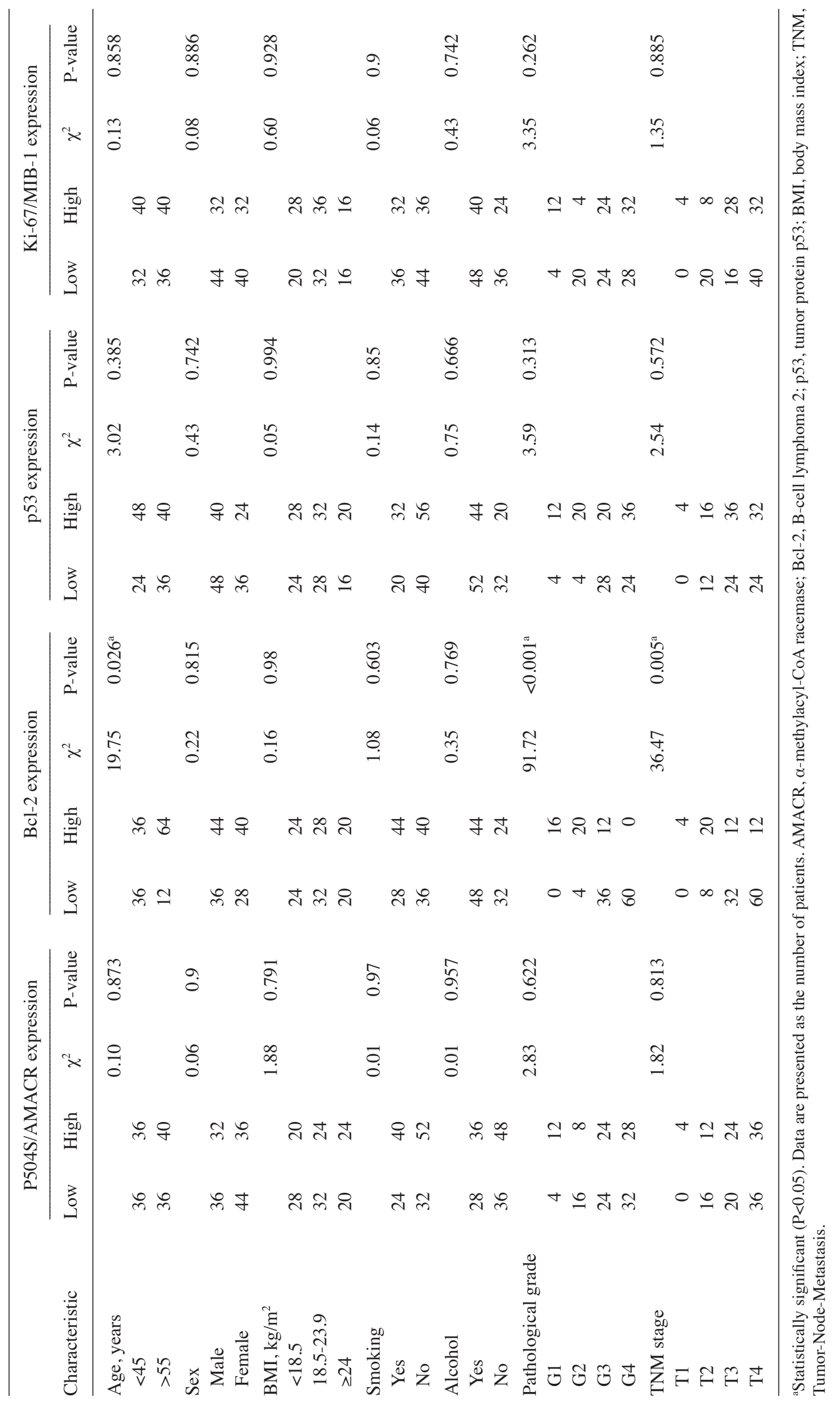


Table IV. Multivariate Cox regression analyses of four proteins as prognostic indicators of colorectal carcinoma.

Multivariate analysis

Variable

Relative risk (95\% confidence interval)

P-value

P504S/AMACR (low vs. high)

$0.982(0.843-1.114)$

0.816

Bcl-2 (low vs. high)

$0.703(0.552-0.895)$

$0.004^{\mathrm{a}}$

p53 (low vs. high)

$0.922(0.731-1.162)$

0.492

Ki-67/MIB-1 (low vs. high)

$1.024(0.763-1.375)$

0.873

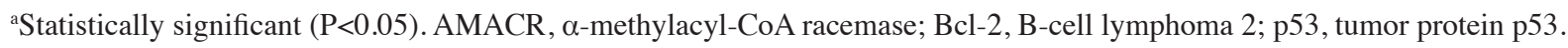
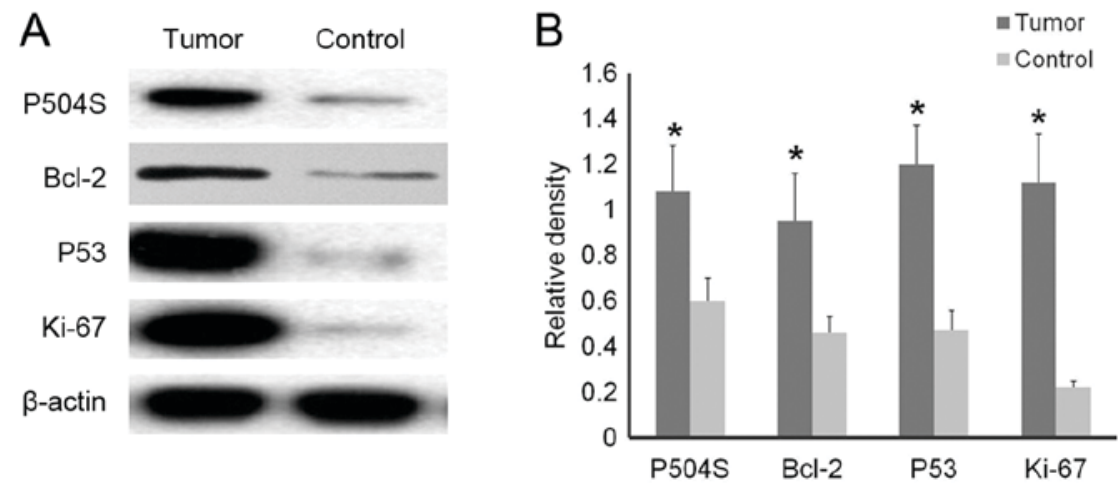

Figure 2. Western blot analysis of the four proteins in the colorectal tumors and matching normal tissue margins (control). (A) Western blot analysis of the four proteins. (B) Expression levels of the four proteins normalized to $\beta$-actin. "P<0.001. P504S, $\alpha$-methylacyl-CoA racemase; Bcl-2, B-cell lymphoma 2; p53, tumor protein $\mathrm{p} 53$.
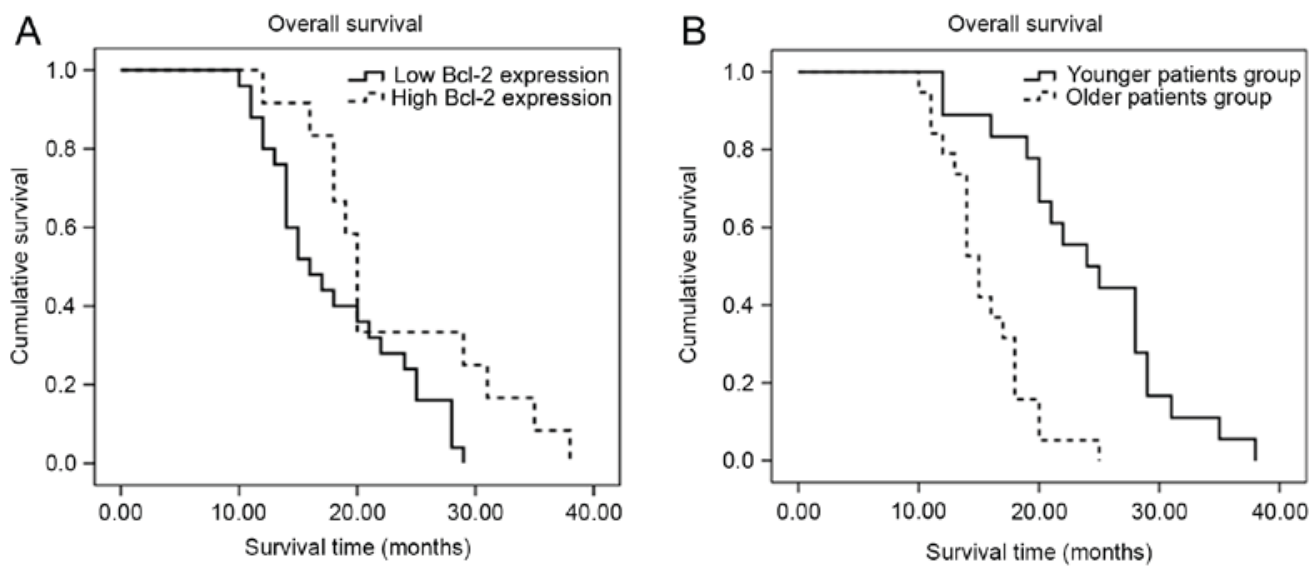

Figure 3. Survival analysis using the Kaplan-Meier method. (A) The association between Bcl-2 expression and overall survival time in Chinese patients with colorectal carcinoma (log-rank $\mathrm{P}=0.039$ ). (B) Subgroup analysis of overall survival time comparing younger ( $<45$ years) and older $(>55$ years) Chinese patients with colorectal cancer (log-rank $\mathrm{P}<0.001)$. Bcl-2, B-cell lymphoma 2.

colorectal carcinoma. However, in contrast to these findings, other studies have revealed no significant association between Bcl-2 expression and prognosis in patients with colorectal cancer (25-28). Despite numerous clinical investigations, there remains no clear-cut association between $\mathrm{Bcl}-2$ expression and clinical outcomes in patients with colorectal carcinoma.

As stated earlier, non-polypoidal lesions and de novo colorectal neoplasms (i.e., without preceding adenoma) occur more commonly in Asian patients (2). Due to the lower incidence of adenoma-like colorectal tumors in Asian populations and the association between $\mathrm{Bcl}-2$ and an adenomatous differentiated phenotype, it is likely that a lower Bcl-2 expression would be associated with less differentiated, more aggressive colorectal tumors and worse clinical outcomes in Asian patients, which is precisely what was observed in the Chinese patient population enrolled in the present study. Further studies in Chinese and other East Asian (e.g., Japanese and Korean) populations that correlate gross pathological examination (by surgery or endoscopy) with the 
histopathological and molecular observations are required to validate this hypothesis.

There are several limitations to the present study. To begin with, the sample size used was limited to only 47 patients; a larger sample size would have provided more reliable statistical results. Additionally, only three risk factors for colorectal carcinoma (BMI, smoking status and excessive alcohol consumption) were assessed in the present study. Other risk factors, including a current diagnosis of type-2 diabetes, a previous diagnosis of colorectal cancer, colorectal adenoma/polyps or inflammatory bowel disease (IBD), and a family history of colorectal cancer or colorectal adenoma/polyps, require further investigation in future studies. Furthermore, due to resource limitations, the expression levels of only four proteins, P504S/AMACR, p53, Bcl-2 and $\mathrm{Ki}-67 / \mathrm{MIB}-1$, were analyzed in the present study. Other proteins that have been previously associated with IBD and colorectal malignancy, including adenomatous polyposis coli, retinoblastoma, deleted in colon cancer and v-Ki-ras2 Kirsten rat sarcoma viral oncogene homolog, also require further investigation in future studies (29). Finally, the present study did not analyze gross tumor morphology, epigenetic factors or the mRNA expression of the proteins examined, all of which may have provided additional insights.

In conclusion, significantly higher expression levels of P504S/AMACR, p53, Bcl-2 and Ki-67/MIB-1 were observed in colorectal tumors than in matched normal tissue margins. Bcl-2 downregulation was revealed to be significantly associated with advanced pathological grade and TNM stage in a Chinese patient population with colorectal carcinoma. Furthermore, it was demonstrated that $\mathrm{Bcl}-2$ downregulation is a prognostic indicator of reduced overall survival time in these patients. Bcl-2 may be a novel target of colorectal carcinoma treatment in the Chinese population of patients.

\section{Acknowledgements}

Not applicable.

\section{Funding}

The present study was supported by the Yongchuan Chongqing Medical University Hospital Fund (grant no. YJYB2012009).

\section{Availability of data and materials}

All the data and materials are available upon reasonable request.

\section{Authors' contributions}

ZL contributed to the study design. GH, QY and LB contributed to data collection. JW contributed to the performance of experiments. BJ and QL contributed to data analysis.

\section{Ethics approval and consent to participate}

The present study was approved by the Ethics Committee (Institutional Review Board) of Yongchuan Hospital, Chongqing Medical University (Chongqing, China). All subjects recruited for the present study provided written informed consent prior to participation.

\section{Consent for publication}

All patients signed informed consent and agreed to the publication of the present research.

\section{Competing interests}

The authors declare that they have no competing interests. The funding body had no role in the study design, data collection and analysis, decision to publish or preparation of the manuscript.

\section{References}

1. Bray F, Ren JS, Masuyer E and Ferlay J: Global estimates of cancer prevalence for 27 sites in the adult population in 2008. Int J Cancer 132: 1133-1145, 2013.

2. Sung JJ, Lau JY, Goh KL and Leung WK; Asia Pacific Working Group on Colorectal Cancer: Increasing incidence of colorectal cancer in Asia: Implications for screening. Lancet Oncol 6: 871-876, 2005.

3. Brenner H, Kloor M and Pox CP: Colorectal cancer. Lancet 383: 1490-1502, 2014.

4. Coghlin C and Murray GI: Biomarkers of colorectal cancer: Recent advances and future challenges. Proteomics Clin Appl 9: 64-71, 2015.

5. Coghlin C and Murray GI: Progress in the identification of plasma biomarkers of colorectal cancer. Proteomics 13: 2227-2228, 2013.

6. Daugherty SE, Platz EA, Shugart YY, Fallin MD, Isaacs WB, Chatterjee N, Welch R, Huang WY and Hayes RB: Variants in the alpha-Methylacyl-CoA racemase gene and the association with advanced distal colorectal adenoma. Cancer Epidemiol Biomarkers Prev 16: 1536-1542, 2007.

7. Kuefer R, Varambally S, Zhou M, Lucas PC, Loeffler M, Wolter H, Mattfeldt T, Hautmann RE, Gschwend JE, Barrette TR, et al: alpha-Methylacyl-CoA racemase: Expression levels of this novel cancer biomarker depend on tumor differentiation. Am J Pathol 161: 841-848, 2002.

8. Sinicrope FA, Ruan SB, Cleary KR, Stephens LC, Lee JJ and Levin B: bcl-2 and p53 oncoprotein expression during colorectal tumorigenesis. Cancer Res 55: 237-241, 1995.

9. Oshima CT, Iriya K and Forones NM: Ki-67 as a prognostic marker in colorectal cancer but not in gastric cancer. Neoplasma 52: 420-424, 2005.

10. Dawson DA, Grant BF, Stinson FS and Zhou Y: Effectiveness of the derived alcohol use disorders identification test (AUDIT-C) in screening for alcohol use disorders and risk drinking in the US general population. Alcohol Clin Exp Res 29: 844-854, 2005.

11. Haining Z, Kawai N, Miyake K, Okada M, Okubo S, Zhang X, Fei Z and Tamiya T: Relation of LAT1/4F2hc expression with pathological grade, proliferation and angiogenesis in human gliomas. BMC Clin Pathol 12: 4, 2012.

12. Edge SB and Compton CC: The American Joint Committee on Cancer: The 7th edition of the AJCC cancer staging manual and the future of TNM. Ann Surg Oncol 17: 1471-1474, 2010.

13. Goel MK, Khanna P and Kishore J: Understanding survival analysis: Kaplan-Meier estimate. Int J Ayurveda Res 1: 274-278, 2010.

14. Kelly PN and Strasser A: The role of Bcl-2 and its pro-survival relatives in tumourigenesis and cancer therapy. Cell Death Differ 18: 1414-1424, 2011.

15. Strasser A, O'Connor L and Dixit VM: Apoptosis signaling. Annu Rev Biochem 69: 217-245, 2000.

16. Hanahan D and Weinberg RA: Hallmarks of cancer: The next generation. Cell 144: 646-674, 2011.

17. Thomas S, Quinn BA, Das SK, Dash R, Emdad L, Dasgupta S, Wang XY, Dent P, Reed JC, Pellecchia M, et al: Targeting the Bcl-2 family for cancer therapy. Expert Opin Ther Targets 17: $61-75,2013$

18. Hague A, Moorghen M, Hicks D, Chapman M and Paraskeva C: BCL-2 expression in human colorectal adenomas and carcinomas. Oncogene 9: 3367-3370, 1994. 
19. Biden KG, Simms LA, Cummings M, Buttenshaw R, Schoch E, Searle J, Gobe G, Jass JR, Meltzer SJ, Leggett BA and Young J: Expression of Bcl-2 protein is decreased in colorectal adenocarcinomas with microsatellite instability. Oncogene 18: 1245-1249, 1999.

20. Shanmugam C, Katkoori VR, Jhala NC, Grizzle WE, Siegal GP and Manne U: p53 Nuclear accumulation and Bcl-2 expression in contiguous adenomatous components of colorectal adenocarcinomas predict aggressive tumor behavior. J Histochem Cytochem 56: 305-312, 2008.

21. Ofner D, Riehemann K, Maier H, Riedmann B, Nehoda H, Tötsch M, Böcker W, Jasani B and Schmid KW: Immunohistochemically detectable bcl-2 expression in colorectal carcinoma: Correlation with tumour stage and patient survival. Br J Cancer 72: 981-985, 1995.

22. Baretton GB, Diebold J, Christoforis G, Vogt M, Müller C, Dopfer K, Schneiderbanger K, Schmidt M and Löhrs U: Apoptosis and immunohistochemical bcl-2 expression in colorectal adenomas and carcinomas. Aspects of carcinogenesis and prognostic significance. Cancer 77: 255-264, 1996.

23. Sinicrope FA, Hart J, Michelassi F and Lee JJ: Prognostic value of bcl-2 oncoprotein expression in stage II colon carcinoma. Clin Cancer Res 1: 1103-1110, 1995.

24. Bhatavdekar JM, Patel DD, Ghosh N, Chikhlikar PR, Trivedi TI, Suthar TP, Doctor SS, Shah NG and Balar DB: Coexpression of Bcl-2, c-Myc, and p53 oncoproteins as prognostic discriminants in patients with colorectal carcinoma. Dis Colon Rectum 40: 785-790, 1997
25. Bukholm IK and Nesland JM: Protein expression of p53, p21 (WAF1/CIP1), bcl-2, Bax, cyclin D1 and pRb in human colon carcinomas. Virchows Arch 436: 224-228, 2000.

26. Bosari S, Moneghini L, Graziani D, Lee AK, Murray JJ, Coggi G and Viale G: bcl-2 oncoprotein in colorectal hyperplastic polyps, adenomas, and adenocarcinomas. Hum Pathol 26: 534-540, 1995.

27. Tollenaar RA, van Krieken JH, van Slooten HJ, Bruinvels DJ, Nelemans KM, van den Broek LJ, Hermans J and van Dierendonck JH: Immunohistochemical detection of p53 and Bcl-2 in colorectal carcinoma: No evidence for prognostic significance. Br J Cancer 77: 1842-1847, 1998.

28. Kaklamanis L, Savage A, Whitehouse R, Doussis-Anagnostopoulou I, Biddolph S, Tsiotos P, Mortensen N, Gatter KC and Harris AL: Bcl-2 protein expression: Association with p53 and prognosis in colorectal cancer. Br J Cancer 77: 1864-1869, 1998.

29. Matkowskyj KA, Chen ZE, Rao MS and Yang GY: Dysplastic lesions in inflammatory bowel disease: Molecular pathogenesis to morphology. Arch Pathol Lab Med 137: 338-350, 2013.

This work is licensed under a Creative Commons Attribution-NonCommercial-NoDerivatives 4.0 International (CC BY-NC-ND 4.0) License. 